\title{
IMPLEMENTING CRYPTOGRAPHIC TECHNIQUES FOR SHARING FILES USING ACCESS CONTROL
}

\author{
Aavula Ravi ${ }^{1}$, K. Satwik Raj ${ }^{2}$, M. Giridhar Reddy ${ }^{3}$, M. Soma Sundar Srikar ${ }^{4}$ \\ ${ }^{1}$ Associate Professor, Department of CSE, GNITC, Ibrahimpatnam, Telangana, India \\ ${ }^{2}$ Department of CSE, GNITC, Ibrahimpatnam, Telangana, India \\ ${ }^{3}$ Department of CSE, GNITC, Ibrahimpatnam, Telangana, India \\ ${ }^{4}$ Department of CSE, GNITC, Ibrahimpatnam, Telangana, India
}

\section{Abstract}

The proposed model is required to meet the requirements of security in data center of cloud. AES is used for the encryption of file slices takes minimum time and has maximum throughput for encryption and decryption from other symmetric algorithms. The idea of splitting and merging adds on to meet the data security. When the hybrid method is used in cloud environment it makes the remote server more secure and helps the cloud providers to earn more users trust. For data security and privacy protection, fundamental challenge of separation of sensitive data and access control is fulfilled. Cryptography is a technique that translates original data into unreadable form. Cryptography technique is classified as symmetric key cryptography and public key cryptography. This technique uses keys to translate readable data into unreadable form. So that only authorized person gets access to the data from cloud server. Cipher text data is visible for all people.

Keywords- AES algorithm, cryptography techniques, file transfer, secure file

\section{INTRODUCTION}

Cloud storage systems have been the source of attraction for the online users so as to have easy access anywhere and anytime. Many online service providers have thrived to serve the individual users, industrialists as well as the business people to have their data on cloud with reliability and security. The numbers of mobile users who need to use the resources or services on the go with the help of their mobile devices from cloud-based systems are rapidly increasing. The process of utilizing the cloud resources for storage and transition of data by mobile users is a challenging task. The cloud environment provided by the online service providers can be in the type of public, private or hybrid cloud. The cloud user selects the type of cloud environment based on the users' decision to privacy or exposure policy.

Many IT giants are using the cloud services to reduce the on-premises cost which is greater than they provide for the online service providers. The cloud system provided by different vendors exhibits the heterogeneity with respect to performance and pricing. The design techniques are varied to achieve competitive results in terms of efficient service, reduced cost, secured data storage. The overall benefits of the cloud system are easy sharing, syncing, off-site data storage, better remote accessibility, reduction of internal IT costs, reduced requirement of resources and online data collaboration.

\section{SURVEY}

The process of secure file sharing is basically concerned with revealing of the data. [1] This paper titled "Secure Cloud Storage and File Sharing" is used for the understanding of Internet-based online cloud 
DOI: https://dx.doi.org/10.26808/rs.ca.i8v2.17 International Journal of Computer Application (2250-1797)

Issue 8 Volume 2, March-April 2018

services provide enormous volumes of storage space, tailor made computing resources and eradicates the obligation of native machines for data maintenance as well. [2] This paper titled "Secure File Sharing Scheme for Mobile Devices" is used for understanding of an ideal file sharing method is all mobile users can directly share their files one-to-one in the mobile peer-to-peer environment. [3] This paper titled "Secure File Sharing Using Cryptographic Techniques in Cloud" is used for understanding of facility of secure storing and sharing the data for dynamic groups in the cloud. By using group signature and encryption techniques any cloud users can efficiently share their data in untrusted cloud.

\section{PROPOSED SYSTEM}

Data owner has to register in trusted third-party system for keeping the files in cloud environment. Data owners create the login credentials for uploading files and those credentials are also used to upload the user lists and their permissions. After receiving a particular file from the data owner, the TTP generates keys by using asymmetric key encryption. Asymmetric key generation is not discussed in this paper and it is assumed that any standard asymmetric key generation algorithm (APKI) is utilized for this purpose.

\section{IMPLEMENTATION}

- Install and run application on your mobile via debugger and login or register.

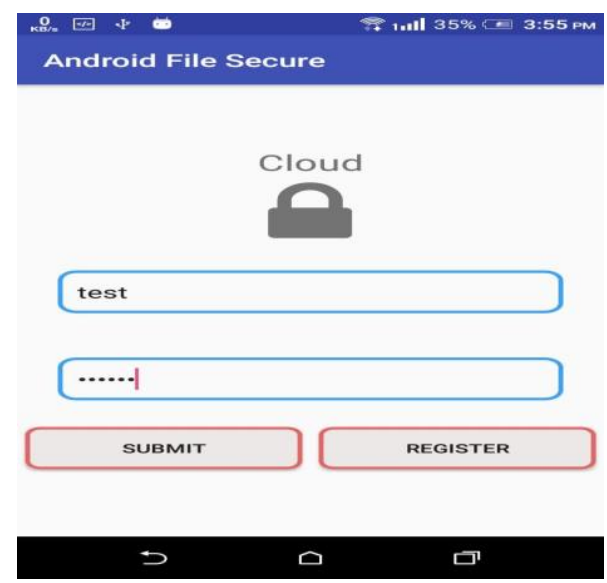

Fig. 1 Login with credentials

- Go to menu tray and open upload files

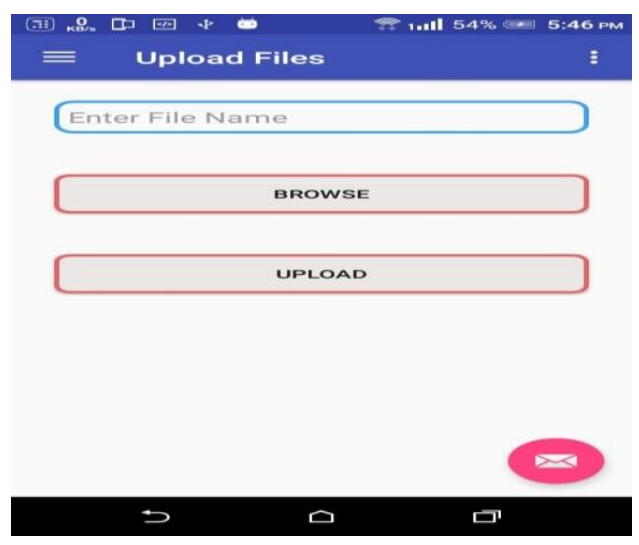

Fig. 2 Upload Files section 
DOI: https://dx.doi.org/10.26808/rs.ca.i8v2.17 International Journal of Computer Application (2250-1797) Issue 8 Volume 2, March-April 2018

- Enter the file name to be uploaded or browse the file

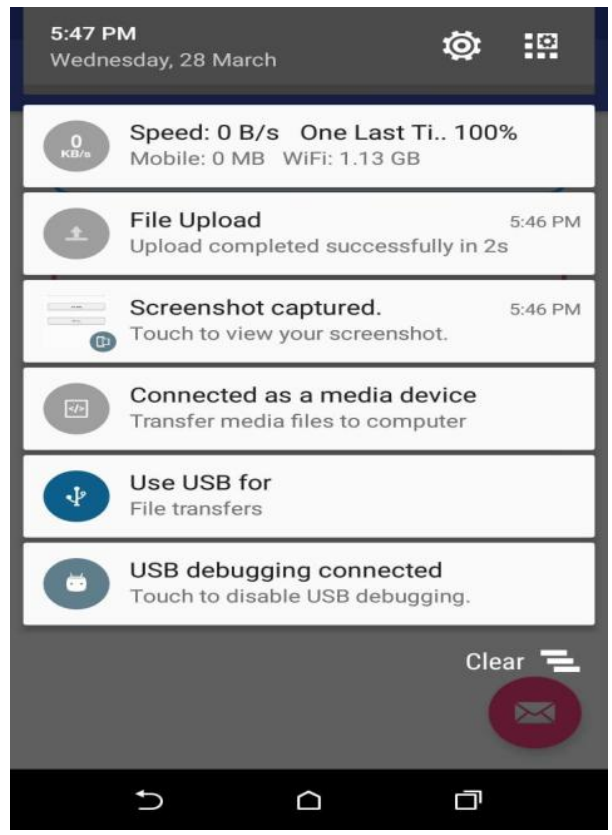

Fig. 3 Progress of file being uploaded

- Uploaded files can be checked in the uploaded files section

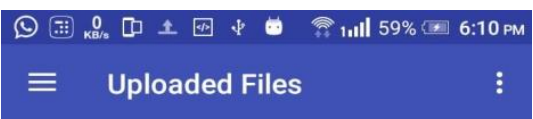

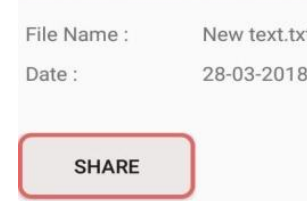

DOWNLOAD

\section{$\supset \quad \square \quad \square$}

Fig. 4 Uploaded files tab 
DOI: https://dx.doi.org/10.26808/rs.ca.i8v2.17 International Journal of Computer Application (2250-1797) Issue 8 Volume 2, March-April 2018

- Enter the username of the person you want to share the files with.
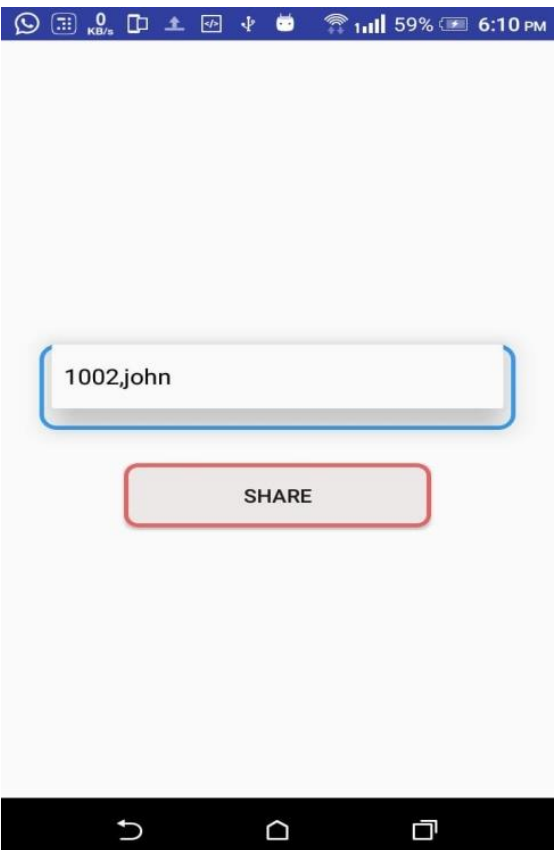

Fig. 5 Sharing the file with desired user

- After entering the username share the files using share button

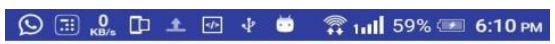

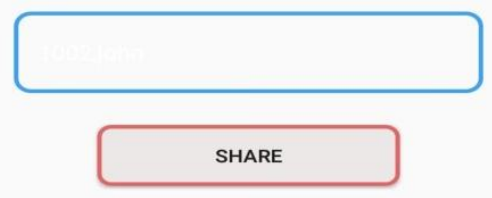

successfully shared

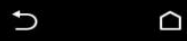

$\square$

Fig. 6 In the above screenshot we can see that the file has been shared successfully 
DOI: https://dx.doi.org/10.26808/rs.ca.i8v2.17 International Journal of Computer Application (2250-1797) Issue 8 Volume 2, March-April 2018

\section{RESULTS}

- To verify whether the file has been shared successfully login with John's (Person whom we shared our fles with) credentials.

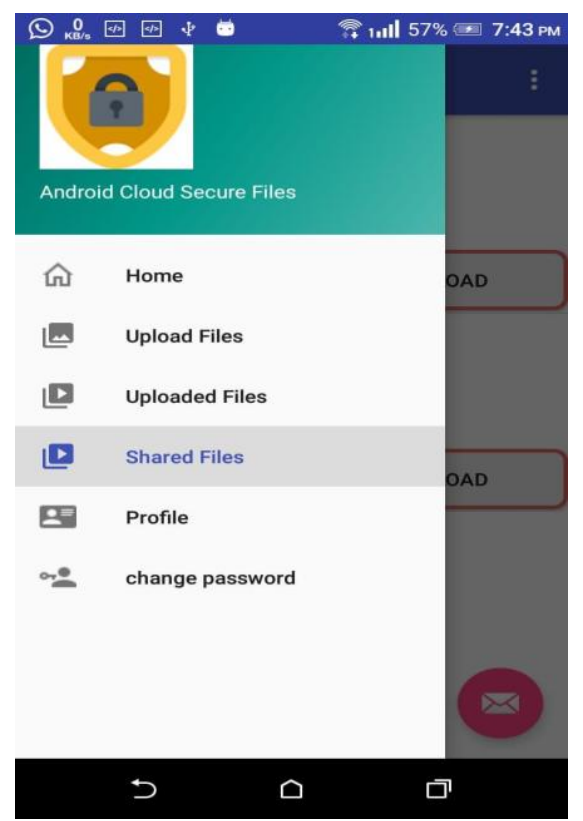

Fig. 7 Logged in John's credentials and opening shared files

- After opening the Shared files tab you'll be redirected to the page with the list of shared files.

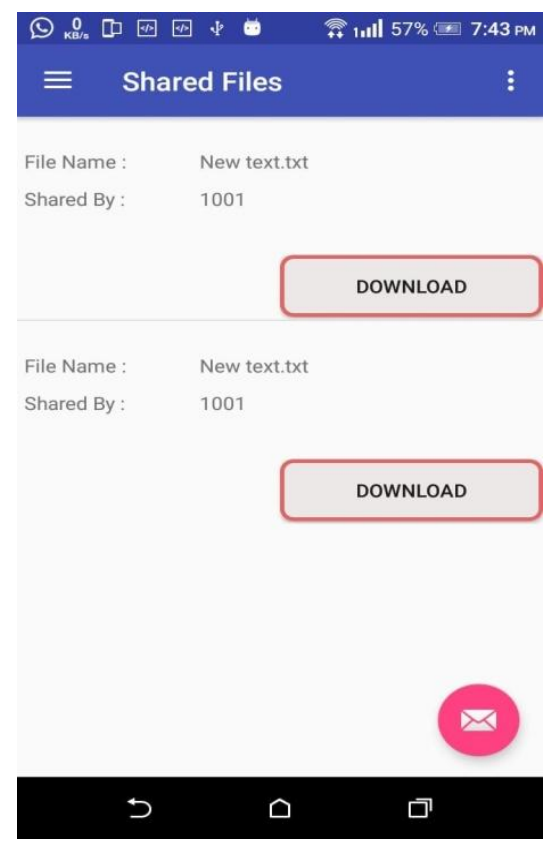

Fig. 8 List of shared files 
- Download the shared file by pressing download and logout after completion.

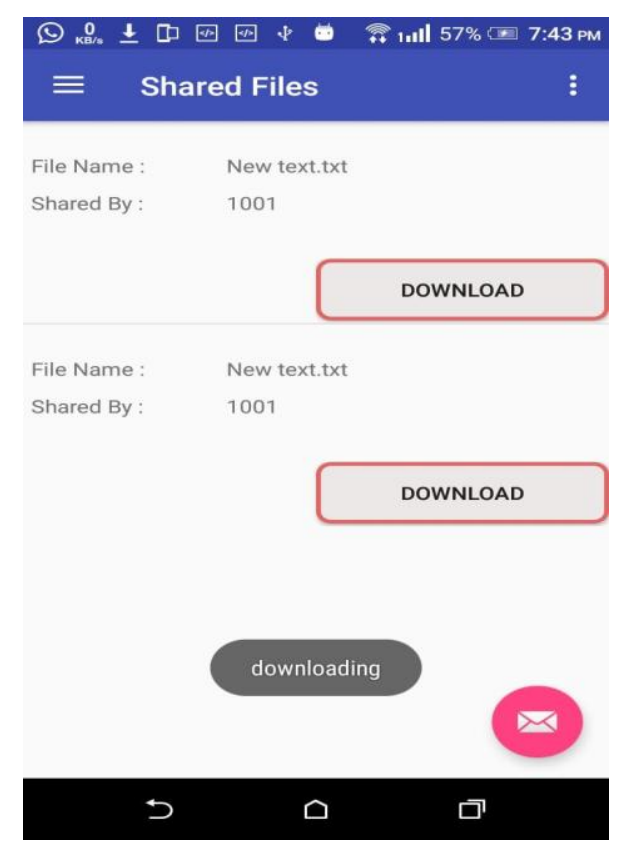

Fig. 9 File is being downloaded

\section{CONCLUSION}

The application developed enable us to share files over cloud securely. This application uses AES algorithm for encryption and decryption. A user has the ability to share the files only with the users they wish to. AES uses higher length key sizes such as 128, 192 and 256 bits for encryption. Hence it makes AES algorithm more robust against hacking. AES is mostly used for applications such as wireless communication, financial transactions, e-business, encrypted data storage etc. Reason for choosing AES is it is fast and unlike DES, the number of rounds in AES is variable and depends on the length of the key.

\section{FUTURE ENHANCEMENT}

This Application provides users the ability to share data over cloud more securely. In current stage the data that can be shared is limited and can be increased with the requirement of it. Various other encryption algorithms can be used with to meet specific needs from the application Servers can be improved for better interaction with the shared files. Various databases can be used to store large amounts of data.

\section{REFERENCES}

[1] Bharat S. Rawal, S. Sree Vivek (2017) "Secure Cloud Storage and File Sharing".

[2] Kuo-Hsuan Huang , En-Chi Chang, Chen-Lin Chang (2014) "Secure File Sharing Scheme for Mobile Devices".

[3] M. Malarvizhi , J. Angela Jennifa Sujana , T. Revathi (2014) "Secure File Sharing Using Cryptographic Techniques in Cloud".

[4] Samaneh Navabpour, Negin F. Nejad Asl, Maghsoud Abbaspour, and Akbar Behzadi (2006)

"Secure Routing in Structured Peer to Peer File-Sharing Networks". 